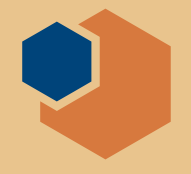

\title{
Materials R\&D priorities shift in US budget proposal for 2022
}

$\mathrm{I}^{\mathrm{n}}$ n late May, the US Biden-Harris administration released a proposed USD\$6 trillion budget for fiscal year (FY) (2022), which lays out the plan for a dramatic increase in US federal spending, reflecting an economic agenda that the administration suggests will help boost an economy and R\&D landscape severely damaged by the COVID-19 pandemic.

The budget proposal, which is an opening bid in negotiations with the US Congress and is expected to change before being signed into law, calls for the most sustained period of spending in more than half a century. The budget invests heavily in President Joe Biden's top priority areas of infrastructure, education, research, and public health.

Starting with the US Department of Defense (DoD), Biden's Pentagon budget request totals USD \$715 billion, which is USD $\$ 7$ billion less than the USD\$722 billion the Trump administration had been eying for its fiscal 2022 submissions. This year's DoD budget is USD $\$ 704$ billion, making Biden's request a $1.4 \%$ increase over 2021 actuals.

While the budget plan requests the largest research, development, test and evaluation top line ever, it simultaneously calls for cutting defense science and technology funding within the larger portfolio by over USD $\$ 2$ billion compared to the 2021 enacted budget. The proposal also requests cutting defense basic research, the type of research that makes discoveries to enable future technologies and military capabilities, by almost 15 percent. According to the Office of Management and Budget, the FY 2022 budget request would result in a cut of $1 \%$ for defense $\mathrm{R} \& \mathrm{D}, 11 \%$ for basic research, and $16 \%$ in applied research.

The FY 2022 budget not only requests basic research cuts versus FY 2021 enacted, but also requests cuts

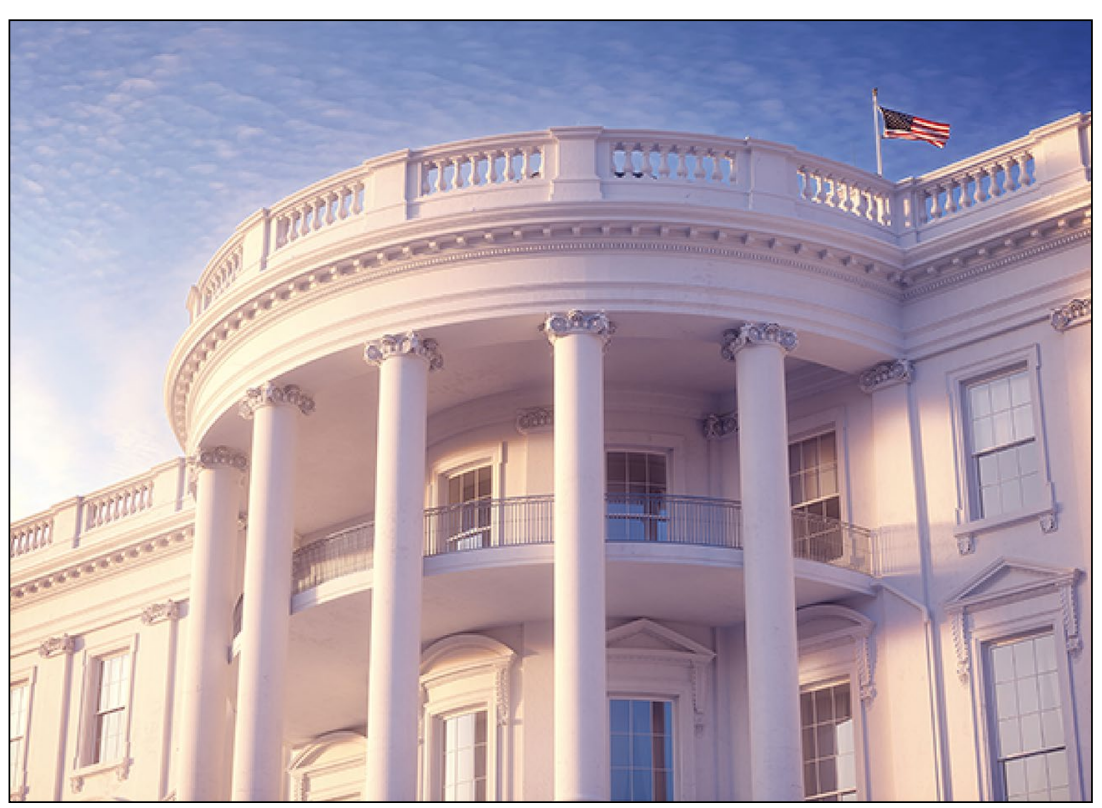

compared to the DoD FY 2021 budget request. Specifically, the current budget calls for:

- $1.6 \%$ cut requested for overall 6.1 Basic Research

- $2 \%$ cut requested for Army Defense Research Sciences

- $0.2 \%$ cut requested for Army University Research Initiatives

- $0.2 \%$ cut requested for Navy Basic Research

- $0.3 \%$ cut requested for Air Force Basic Research

- $19.1 \%$ cut requested for Defense Threat Reduction Agency Basic Research Initiatives

- $5.7 \%$ cut requested for DefenseWide Basic Research

While the budget makes significant cuts to DoD basic research, federal agencies that support research fared much better, receiving moderate proposed increases over FY 2021. One example is that the administration is seeking to increase the budget of the National Science Foundation (NSF) to USD \$10.2 billion.

NSF's research directorates would also receive funding increases under the request, ranging from $7 \%$ for the Mathematical and Physical Sciences Directorate to $\sim 20 \%$ for the Geosciences and Engineering Directorates. The budget would also create a new Technology Directorate. Consistent with the US Senate version of the United States Innovation and Competition Act (USICA - the former Endless Frontiers Act) and the US House of Representatives' version of the NSF for the Future Act (a bill that reauthorizes the NSF and includes a few elements of the NSF section of the USICA), the budget focuses on technology commercialization and societal challenges. 
The budget requests USD $\$ 865$ million to launch the new NSF directorate, USD $\$ 500$ million of which would be new funding. Legislative proposals just mentioned would fund the new directorate at amounts up to USD\$29 billion.

Artificial intelligence (AI) research funding under the proposal would increase by $20 \%$ to USD $\$ 734$ million, with the National AI Research Institutes program budget increasing $36 \%$ to USD\$69 million. Funding for quantum information sciences would increase by $24 \%$ to USD $\$ 260$ million, with steady funding of USD $\$ 50$ million allocated to the multidisciplinary centers for quantum research and education created pursuant to the National Quantum Initiative Act.
For the US Department of Energy (DOE), the proposed budget seeks a $6 \%$ increase over 2021 enacted for its Office of Science, which translates to just over USD \$7.4 billion. Bills introduced in the House of Representatives would recommend Congress appropriate USD $\$ 8.8$ billion to the Office for FY 2022, rising to USD\$11.1 billion by FY 2026.

The administration's request also offers details on a number of new program proposals and project developments within DOE. These include proposals to create office-wide programs in science-technology-engineering-mathematics training for underrepresented communities and in climate research. In addition, the request discusses new standalone programs for accelerator technology and isotope production, and it reports that cost estimates for a number of construction projects have significantly increased from the 2021 enacted figures.

Under the request, the DOE Basic Energy Sciences budget would increase $2 \%$ to USD $\$ 2.3$ billion. Construction funding would decrease as the budget profiles ramp down for upgrades in progress at the Spallation Neutron Source and Advanced Photon Source facilities, while budgets for other projects would be kept generally flat.

Overall, while the administration's budget proposal presents challenges in the areas of DoD funding, federal agency budgets would see an increase if these recommendations would become law.

Damon Dozier

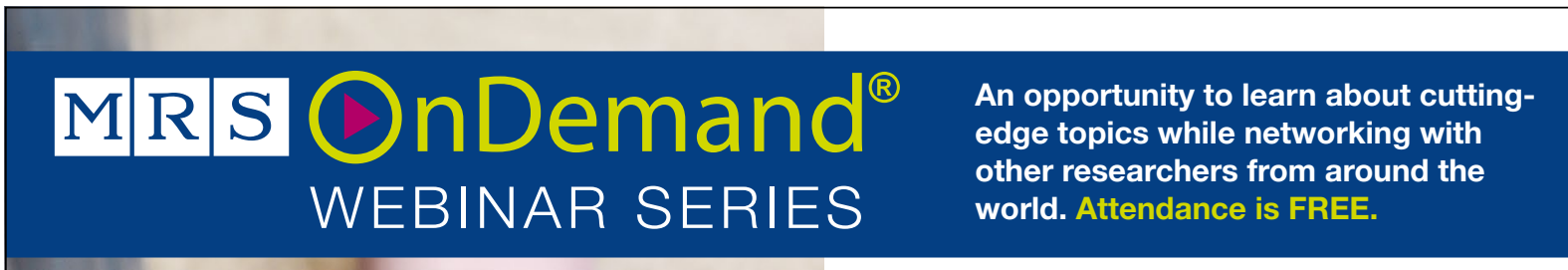
UPCOMING WEBINARS
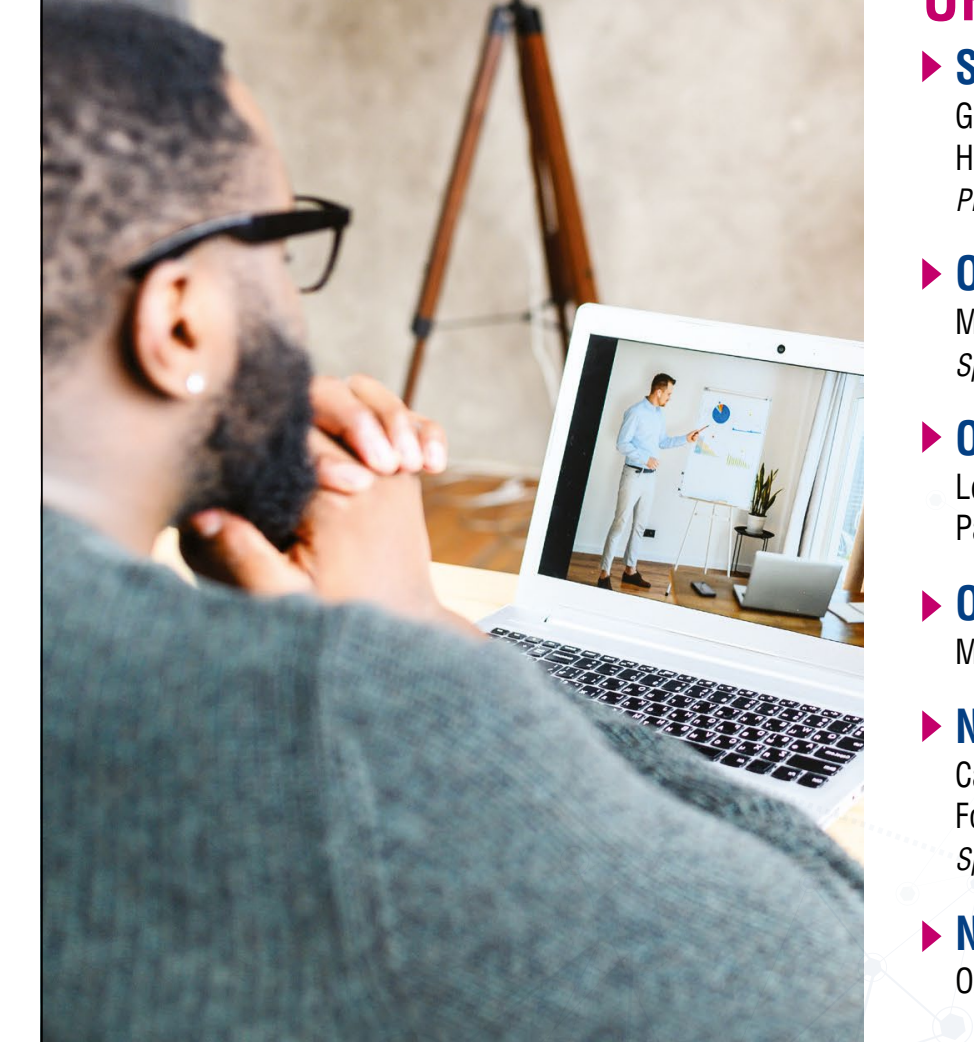

September 29, 2021

Green Cards for Scientific Researchers:

How to win your EB-1/NIW case

Presented by Getson \& Schatz

October 20, 2021

MRS Career Discovery Series: Focus on Biomaterials Sponsored by the PPG Foundation

\section{October 26, 2021}

Learn from the Early Career Faculty Webinar SeriesPart III: The Offer and Next Steps

October 27, 2021

Materials Opportunities for Low-Energy Computing

\section{- November 16, 2021}

Career Discovery Series:

Focus On Quantum and Nanomaterials

Sponsored by the PPG Foundation

- November 17, 2021

Oxide Electronics 